\title{
O PAPEL DA EDUCAÇÃO AMBIENTAL NO DESENVOLVIMENTO DA PERCEPÇÃO DOS RISCOS DE INUNDAÇÕES E PREVENÇÃO DE ACIDENTES E DESASTRES NATURAIS
}

\author{
Nair Júlia Andrade de Abreu ${ }^{1}$ \\ Maria Eliza Zanella ${ }^{2}$ \\ Marysol Dantas de Medeiros ${ }^{3}$
}

Resumo: Os riscos de inundações fazem parte da realidade brasileira e consistem na possibilidade das inundações resultarem em acidentes com prejuízos materiais e até mesmo humanos, podendo configurar até mesmo desastres naturais. Constituem, portanto, uma problemática preocupante para a sociedade, que diante disso, precisa e deve lutar para a minimização e/ou eliminação dos mesmos. No entanto, para que isso ocorra, é necessário primeiramente que as pessoas estejam conscientes desses riscos, e nesse caso, a educação ambiental (EA) pode contribuir significativamente. Com base nisso, o objetivo desse artigo consiste em discutir o papel da EA no desenvolvimento da percepção desses riscos e na prevenção de acidentes ou até mesmo de desastres naturais.

Palavras-chave: Inundações; Riscos; Percepção; Educação Ambiental.

\footnotetext{
1 Universidade Federal do Ceará. E-mail: nairaandradi@yahoo.com.br

2 Universidade Federal do Ceará. E-mail: elisazv@terra.com.br

3 Universidade Federal do Ceará. E-mail: marysol0112@hotmail.com
} 


\section{Introdução}

Os riscos ambientais figuram entre os problemas que se apresentam à sociedade brasileira, entre eles, destacam-se aqui, os riscos de inundações, presentes principalmente em áreas urbanas, onde se observa quantidade significativa de pessoas vivendo nas margens de rios e riachos, sendo que muitas delas já sofreram impactos de inundações. Esses riscos representam a possibilidade de as pessoas serem afetadas negativamente pela ocorrência de inundações, seja através de danos materiais como também humanos.

Em alguns casos, as pessoas não percebem esses riscos, especialmente quando nunca foram afetadas. Há também aquelas que percebem os riscos, mas ignora-os, convivendo naturalmente com eles, sem tomar nenhuma providência, algumas por falta de condições financeiras, outras por falta de conhecimento, de orientação ou ainda por comodismo. Esses aspectos podem contribuir para que os riscos se concretizem e ocorram muitas consequências negativas, como perdas de bens materiais, mortes, entre outras, inclusive já registradas em vários municípios brasileiros.

Nesse contexto, o presente artigo objetiva apontar a educação ambiental (EA) como um importante instrumento no desenvolvimento da percepção mais "acurada" desses riscos e na prevenção de acidentes e até mesmo de desastres naturais associados às inundações. Ressalta-se aqui, o fato de que na medida em que a EA abordar os diversos fatores que condicionam as inundações e potencializam suas consequências, ela poderá levar as pessoas a identificarem os riscos aos quais estão expostas e terem consciência da gravidade, das consequências a eles associadas, tornando-se, portanto, mais viável conscientizá-las quanto à importância de se evitar ações que potencializam as inundações (e seus efeitos) e tomar providências que reduzam ou eliminem os danos que podem resultar das mesmas.

Tratando dos condicionantes das inundações, especificamente daqueles denominados como antrópicos, como o acúmulo de lixo nas margens dos rios e até mesmo dentro deles, a EA pode colaborar também para desenvolver nas pessoas, um maior nível de conscientização quanto ao fato de que ao ignorar a importância de se conservar o meio ambiente e comprometer o equilíbrio ecológico, o ser humano está comprometendo também à sua qualidade de vida e favorecendo a produção ou intensificação de riscos ambientais. Tudo isso pode contribuir para que as pessoas reflitam e adotem práticas conservacionistas, que nesse caso, também assumirão caráter preventivo, já que podem colaborar para a redução de riscos ambientais.

A metodologia adotada no desenvolvimento deste trabalho consistiu inicialmente no levantamento e revisão bibliográfica sobre riscos ambientais (especialmente sobre riscos de inundações), percepção de riscos, inundações e sobre a educação ambiental, incluindo a Lei 9.795/99 e as diversas concepções sobre seu papel e importância frente aos riscos de inundações. Procedeu-se então a redação do artigo, destacando-se e discutindo-se os aspectos considerados mais relevantes.

Revbea, São Paulo, V. 11, № 1: 97-107, 2016. 


\section{Os riscos e a percepção que se desenvolve sobre eles}

O vocábulo risco refere-se a algo que não aconteceu, mas que pode acontecer, resultando em danos tanto moderados como até mesmo gravíssimos ao ser humano. Veyret (2007) define-o como uma catástrofe possível, a tradução de uma ameaça, de um perigo, ressaltando que o mesmo existe somente quando há um indivíduo, uma população que o perceba e possa sofrer seus efeitos.

O risco associa-se às noções de incerteza, exposição ao perigo, perdas e prejuízos materiais, econômicos e humanos, em função de processos de ordem natural e/ou daqueles associados ao trabalho e às relações humanas. Refere-se à probabilidade de ocorrência de processos no tempo e no espaço, não constantes e não determinados (CASTRO, 2005, p.12)

Faz-se necessário destacar que nos estudos sobre o tema, elencam-se diferentes tipos de risco. Veyret (2007), por exemplo, propõe os seguintes: ambientais, naturais, industriais e tecnológicos, geopolíticos, econômicos e sociais. Alguns autores falam ainda em riscos socioambientais.

Observando-se as definições de risco ambiental, compreende-se que os riscos de inundações se enquadram nessa categoria, como se pode comprovar nas definições abaixo.

Os riscos ambientais são aqueles que resultam da associação entre os riscos naturais e os riscos decorrentes de processos naturais agravados pela atividade humana e pela ocupação do território (VEYRET, 2007, p. 63). Ou seja, são os que existem onde há a possibilidade de ocorrer um evento natural intenso (como terremotos, deslizamentos e inundações, por exemplo) em áreas ocupadas pelo ser humano.

Souza e Zanella (2009, p.16) afirmam que "a expressão risco ambiental refere-se a uma situação de ameaça ambiental (de ordem física, tecnológica e até mesmo social) atuando sobre uma população reconhecidamente vulnerável'.

As definições expostas são apropriadas, pois os riscos de inundações realmente envolvem aspectos naturais, como a possibilidade de ocorrência de eventos pluviométricos intensos e fragilidade da planície de inundação, bem como fatores sociais, que consistem no fato de o ser humano ocupar essas áreas.

Entre as diferentes abordagens sobre riscos, têm sido desenvolvidos estudos sobre a percepção dos mesmos. Faz-se necessário ressaltar que o entendimento da mesma passa pelo conhecimento da percepção humana de forma mais geral e não apenas daquela relacionada exclusivamente aos riscos.

Para Cardozo (2009, p.28) "A percepção é, por excelência, um fenômeno psicológico, social e coletivo, uma vez que congrega todos os sentidos para conferir um significado ao que é vivido pelo sujeito". 
Conforme Machado (1999, p.9), a percepção pode ser definida como "o significado que atribuímos às informações recebidas pelos nossos sentidos, como sensações. Assim colocada, a percepção é o conhecimento que adquirimos através do contato direto e imediato com os objetos e com seus movimentos, dentro do espaço sensorial".

Abordando-se especificamente a percepção de riscos, ressalta-se que ela pode ser definida, segundo Wiedemann (1993,p.3), como a:

... habilidade de interpretar uma situação de potencial dano à saúde ou a vida da pessoa, ou de terceiros, baseada em experiências anteriores e sua extrapolação para um momento futuro, habilidade esta que varia de uma vaga opinião a uma firme convicção.

Whyte (1985, p.115 apud SOUZA; ZANELLA, 2009, p.35), conceitua a expressão risk perception como "The process where by risks are subjectively, orintuitively, understood and evaluated", destacando que no processo de percepção, os riscos são avaliados como aspecto objetivo da realidade, mas com certa dose de intuição.

Baseando-se nos autores citados e em várias pesquisas sobre o assunto, é possível inferir que, assim como a percepção humana de forma geral, a percepção que os indivíduos apresentam frente aos riscos envolve uma gama de fatores e por isso, verifica-se muitas vezes, diferentes formas de perceber os riscos ambientais. Isso se dá em função de aspectos como o tipo de risco, o nível de gravidade dos possíveis danos, o grau de escolaridade do indivíduo, as experiências vivenciadas, o conhecimento que se tem deles, entre outros.

Para exemplificar a influência desses diferentes fatores que atuam sobre a percepção de riscos, convém colocar que quando o risco está relacionado a uma situação que no passado envolveu consequências graves, como a perda de vida humana, por exemplo, ele é percebido com mais facilidade e desse modo, provavelmente, as pessoas não vão ignorá-lo e possivelmente vão adotar medidas preventivas em relação a ele. Por outro lado, quando ele "parece" não apresentar a possibilidade de danos graves, as pessoas tendem a não darem muita importância a ele, podendo nem o perceber, ou saber de sua existência e ignorá-lo, vivendo naturalmente, sem medo, sem precaução.

Burton, Kates e White (1993, apud SOUZA; ZANELLA, 2009, p.37), apontaram fatores que, segundo eles, influenciam as respostas humanas aos eventos naturais extremos: magnitude do evento, frequência em que ocorre, duração, extensão em área, velocidade de desencadeamento, dispersão espacial (linear, pontual), distribuição temporal (sazonal, aleatório). Uma vez que esses aspectos exercem influência sobre a avaliação de eventos já ocorridos, entende-se aqui, que eles também atuam sobre a percepção de riscos, na medida em que as experiências vividas por uma pessoa ficam na Revbea, São Paulo, V. 11, № 1: 97-107, 2016. 
memória e desse modo, interferem em suas convicções, em seu modo de apreender o mundo, de perceber os riscos. Pessoas que vivenciaram um evento de grande magnitude ou que vivem em uma área onde já ocorreu um (mesmo antes delas se instalarem ali) tendem a perceber mais facilmente que existe a possibilidade de acontecerem outros, ou seja, elas tendem a apresentar mais sensibilidade para perceber o(s) risco(s).

Com base no que foi exposto, convém afirmar que as pessoas podem perceber ou não determinados riscos, e dependendo de suas percepções e de outros aspectos, podem ignorá-los ou adotar medidas preventivas. A percepção dos riscos depende de diferentes fatores, entre eles destacam-se nesse artigo, o conhecimento que se tem sobre o processo natural relacionado aos riscos. Ou seja, só é possível perceber os riscos de inundações, por exemplo, quando se tem uma noção do que são inundações e dos fatores que condicionam a ocorrência das mesmas. Já a adoção de medidas preventivas vai depender, além das condições econômicas, da percepção que o indíviduo apresenta sobre os riscos e suas possíveis consequências. É nesse sentido, que se discute nesse artigo, o papel da EA frente aos riscos de inundações, destacando que a mesma pode transmitir e produzir conhecimentos capazes de exercer influência no desenvolvimento de percepções "mais acuradas" sobre os riscos de inundações e no modo de reagir frente a eles.

\section{A Educação Ambiental e seu papel frente aos riscos ambientais}

A educação ambiental é um processo social e político fundamental na construção de estruturas cognitivos e conceituais do indivíduo, pelo fato de desenvolver juízos de valores e percepções (GARCIA, 1993 apud BUSTUS, 2003). Ou seja, a EA exerce influência no desenvolvimento da percepção das pessoas, o que ocorre em função do fato de através dela, é possível transmitir importantes informações, contribuindo para que o indivíduo assimile conhecimentos importantes ao desenvolvimento da percepção ambiental.

A EA deve ser entendida como o processo que permite ao indivíduo compreender as relações de interdependência com seu entorno, a partir do conhecimento reflexivo e crítico de sua realidade biofísica, social, política econômica e cultural, para que, a partir da apropriação da realidade concreta, possam ser geradas atitudes de valorização e respeito por seu ambiente. Essas atitudes, portanto, devem ser fundamentadas em critérios para a melhoria da qualidade de vida e de uma concepção de desenvolvimento sustentável (SANTOS, 2007).

Considerando-se que a EA abrange práticas que contribuem para que 0 indivíduo perceba o ambiente ao seu redor e suas inter-relações, compreendese que a mesma apresenta grande potencial no sentido de favorecer 0 desenvolvimento da percepção de riscos ambientais, já que estes se destacam significativamente dentro da problemática ambiental que vem se revelando à sociedade. Nesse sentido, Souza (2006, p. 57) coloca que: 
Cabe à educação ambiental colaborar para a construção de um conhecimento crítico a respeito dos riscos, além de despertar novos valores ou resgatar valores perdidos, atuando conseqüentemente na formação de atitudes positivas para com o ambiente e com a própria vida.

Campos (1999) também teceu importantes considerações sobre uma educação ambiental voltada para o entendimento dos riscos ambientais e de outros tipos de riscos presentes na sociedade, conforme se destaca na citação abaixo:

La "educación ambiental" constituye un promisorio punto de apoyo para el fomento temprano de una conciencia integral de riesgo entre los jóvenes, es decir, no limitada a los "riesgos de desastre". Ampliación particularmente relevante, porque la educación formal tiene un papel decisivo en la formación de conciencia y responsabilidad ante las variadas formas de riesgo existentes en una sociedad concreta, afectando diferencialmente a sus integrantes (CAMPOS, 1999, p. 54).

Na citação acima, Campos (1999) ressalta a importância da EA formal, ou seja, daquela promovida no âmbito das escolas. Em outras colocações ele enfatiza que no ambiente escolar, as relações cotidianas que são estabelecidas podem favorecer o trabalho de prevenção de acidentes, de desastres naturais. Por outro lado, ele destaca a importância da EA informal atuar sobre a percepção dos riscos e colaborar para a criação de condições para respostas mais adequadas aos eventos perigosos.

No Brasil, a educação ambiental é regulamentada pela lei 9.795 de 1999, que institui a Política Nacional referente à mesma, concebendo-a, em seu artigo $1^{\circ}$ como: "... os processos por meio dos quais o indivíduo e a coletividade constroem valores sociais, conhecimentos, habilidades, atitudes e competências voltadas para a conservação do meio ambiente, bem de uso comum do povo, essencial à sadia qualidade de vida e sua sustentabilidade".

O artigo $4^{\circ}$ da referida lei, destaca os princípios básicos da Educação Ambiental, entre eles o enfoque humanista, holístico e participativo. Ou seja, sugere que ela não pode ser puramente naturalista, mas que deve ser abrangente, incluindo a sustentabilidade da natureza e da sociedade, envolvendo a participação de todos: especialistas, gestores, educadores e comunidade no geral. $O$ presente trabalho tem no referido artigo uma de suas bases, e diferente de alguns trabalhos sobre educação ambiental, ele foca não apenas na conservação dos recursos naturais, mas também no bem-estar, na segurança das pessoas.

Outro princípio destacado na lei mencionada é o de que o conceito, as noções de meio ambiente devem contemplar a sua totalidade, o todo, a interdependência entre o meio natural, o socioeconômico e o cultural, sob o 
enfoque da sustentabilidade. Esse princípio é bastante pertinente a essa discussão, pois é fundamental para se compreender e justificar a relação existente entre a Educação Ambiental e a percepção de riscos ambientais, na medida em que reforça a ideia de que a noção de meio ambiente não inclui somente os elementos naturais, a natureza em si, como algumas pessoas compreendem de forma equivocada, mas também os outros diversos aspectos relacionados ao ser humano, que também compõem a natureza.

De acordo com a resolução CONAMA n 0306 de 2002 o "Meio Ambiente é o conjunto de condições, leis, influências e interações de ordem física, química, biológica, social, cultural e urbanística, que permite, abriga e rege a vida em todas as suas formas". Logo, considerando-se também esse conceito, é possível afirmar que realmente a EA deve enfocar (além de outras temáticas) a questão dos riscos ambientais, entre eles os de inundações, enfocados nessa pesquisa. E ela, não apenas pode, como precisa assumir um papel fundamental diante dessa problemática, tendo como objetivo 0 desenvolvimento de uma percepção "mais acurada" desses riscos, de modo a contribuir para a redução ou até mesmo eliminação de possíveis danos que a sociedade venha a sofrer dada a concretização deles.

Para tratar mais especificamente do papel da Educação Ambiental frente aos riscos de inundações no Brasil e à necessidade de desenvolver nas pessoas uma percepção mais abrangente, "mais acurada" sobre eles, direciona-se agora, para a discussão dos objetivos propostos na lei 9.795/99, utilizando-se deles para justificar e embasar práticas de uma educação ambiental voltada para essa problemática. Os objetivos mencionados encontram-se dispostos no artigo $5^{\circ}$ da referida lei, sendo eles:

I - o desenvolvimento de uma compreensão integrada do meio ambiente em suas múltiplas e complexas relações, envolvendo aspectos ecológicos, psicológicos, legais, políticos, sociais, econômicos, científicos, culturais e éticos;

II - a garantia de democratização das informações ambientais;

III - o estímulo e o fortalecimento de uma consciência crítica sobre a problemática ambiental e social;

IV - o incentivo à participação individual e coletiva, permanente e responsável, na preservação do equilíbrio do meio ambiente, entendendo-se a defesa da qualidade ambiental como um valor inseparável do exercício da cidadania;

V - o estímulo à cooperação entre as diversas regiões do País, em níveis micro e macrorregionais, com vistas à construção de uma sociedade ambientalmente equilibrada, fundada nos princípios da liberdade, igualdade, solidariedade, democracia, justiça social, responsabilidade e sustentabilidade;

VI - o fomento e o fortalecimento da integração com a ciência e a tecnologia;

VII - o fortalecimento da cidadania, autodeterminação dos povos e solidariedade como fundamentos para o futuro da humanidade. 
Dos incisos destacados, são discutidos aqui, os cinco primeiros. O Inciso I pode reforçar a ideia de que a EA pode expor e discutir com as pessoas os condicionantes das inundações, levando-as a entender entre outros aspectos, a relação entre a ação antrópica e os riscos de inundações, pois:

Embora os condicionantes das cheias e inundações tenham a sua origem em fatores naturais, as intervenções antrópicas têm se mostrado determinantes no agravamento das consequências desses fenômenos. O uso e ocupação das planícies naturais de inundação, a obstrução dos cursos d'água por obras hidráulicas inadequadas e pelo lançamento de lixo, a impermeabilização dos solos urbanos dentre outras, são ações que contribuem para agravar o impacto socioeconômico dos eventos de cheias (MEDEIROS, 2011, p. 2).

Ou seja, a EA pode levar as pessoas a entenderem os condicionantes antrópicos das inundações, tais como o acúmulo de lixo e a impermeabilização do solo, pois desse modo, poderá contribuir para que elas evitem ações que reforcem a existência desses condicionantes.

Já o objetivo II serve para justificar a proposta de trabalhar esse assunto com as comunidades, na medida em que destaca a garantia das informações ambientais para todos, revelando o papel da EA no sentido de levar informações ambientais às pessoas, tais como aquelas relacionadas aos riscos de inundações, por exemplo, e orientações sobre possíveis medidas a serem tomadas diante deles.

Ainda com base no objetivo I, ressalta-se que nas atividades de ED voltadas para os riscos de inundações é fundamental que sejam transmitidos conteúdos para que as pessoas que habitam áreas sujeitas a esses riscos compreendam os componentes e relações que caracterizam as planícies fluviais, a fragilidade das mesmas, o que é e como se dá o processo de inundação e como o ser humano pode atuar de modo a reduzir as chances de ocorrerem inundações com danos significativos. Ou seja, deve-se partir da totalidade do meio ambiente, enfocando-se os diversos componentes naturais (clima, relevo, vegetação, solos) e as inter-relações entre eles, bem como a interação do ser humano com estes.

Os educadores ambientais precisam colaborar para que a população perceba que o sistema ambiental, justamente por seu caráter sistêmico, apresenta múltiplas interações entre seus componentes, e que por isso, uma dada ação atua mais diretamente sobre um determinado componente, mas indiretamente compromete os demais, já que todos estão interligados, o que por sua vez compromete o equilíbrio ambiental e consequentemente interfere na vida das pessoas. Desse modo, torna-se mais fácil que as pessoas compreendam como se configuram os riscos e percebam que podem estar 
sujeitas à ocorrência de inundações, mesmo que nunca tenham ocorrido danos significativos na área.

Relacionado o inciso III à temática em questão, pode-se inferir que se deve estimular e fortalecer a consciência de que as ações humanas podem condicionar o aumento dos riscos de inundações, fazendo com que as pessoas reflitam sobre suas ações e assumam novas posturas. É preciso conscientizar as pessoas de que 0 ato de jogar lixo nos canais fluviais e em suas margens pode colaborar para a ocorrência de inundações com consequências mais significativas, na medida em que dificulta o escoamento das águas. Deve-se ressaltar e explicar ainda que o desmatamento nas margens de rios e riachos também acarreta repercussões negativas que refletem na vida humana e nos ecossistemas de modo geral.

É necessário globalizar e contextualizar todas essas informações para que as pessoas tenham uma visão geral, mais abrangente da problemática, tornando-se mais críticas e sendo capazes de compreender a ligação de um problema local, no caso, os riscos de inundação, com o contexto global, pois segundo Morin (1999, p.33) “... não há problemas em uma nação que não estejam ligados a outros de natureza planetária".

Concomitante a isso, contemplando-se o objetivo IV, deve-se incentivar as pessoas a participarem, tanto individualmente, bem como coletivamente, da conservação do meio ambiente, da limpeza do rio e de suas margens, mostrando-Ihes que essa postura se constitui em um ato de cidadania que colabora para que desfrutem de uma vida com mais qualidade, mais segurança. Desse modo, a EA estará estimulando práticas conservacionistas e ao mesmo tempo preventivas.

O inciso $\mathrm{V}$ versa sobre a construção de uma sociedade ambientalmente equilibrada, fundada nos princípios da liberdade, igualdade, solidariedade, democracia, justiça social, responsabilidade e sustentabilidade. A problemática em questão realmente perpassa por esse inciso, ao passo em que a justiça social e a responsabilidade, por exemplo, podem remeter ao fato de que se deve colaborar para que a população tenha consciência de que ela precisa exigir que o poder público tome providências para que as pessoas fiquem menos expostas aos riscos de inundações (promovendo a limpeza dos rios, por exemplo, ou até mesmo providenciando moradias em locais relativamente mais seguros) ou pelo menos, em alguns casos, lhes dê condições de adotar medidas de ajustamentos que lhes possibilite conviver melhor com as inundações ,de forma que possíveis eventos sejam menos impactantes, o que configuraria de certa forma, menos injustiça social e a responsabilidade assumida tanto pelas comunidades bem como pelo governo. É importante que as comunidades tenham consciência de que o poder público tem obrigação de promover medidas frente a esses riscos, o que inclusive está previsto na Constituição Federal, que estabelece, no inciso XVIII do art. 21, que compete à União: "Planejar e promover a defesa permanente contra as calamidades públicas, especialmente as secas e inundações". 


\section{Considerações finais}

Baseando-se no fato de que os riscos ambientais e mais especificamente os de inundações constituem-se em verdadeiras ameaças ao ser humano e, portanto ao meio ambiente, já que aquele é parte deste, e levando-se em conta as diferentes considerações expostas sobre a educação ambiental, os princípios e os objetivos propostos na lei 9.795/99, conclui-se que a EA tem potencial para colaborar com o desenvolvimento da percepção dos riscos de inundações e contribuir para a redução e/ou eliminação de impactos, tanto de modo formal, principalmente nas escolas em que o quadro discente apresenta alunos que vivem em áreas sujeitas às inundações, bem como de modo não formal, sobretudo nas comunidades situadas em planícies fluviais.

Conforme ressaltado em parágrafos anteriores, a percepção do ser humano envolve diferentes fatores, entre eles os conhecimentos que as pessoas apresentam. Logo, acredita-se que, compreendendo o funcionamento de um rio, da planície, do clima, incluindo a ocorrência de eventos pluviométricos intensos, enfim, os diversos fatores que envolvem as inundações, as pessoas se tornarão mais aptas a identificar, a perceber os riscos de inundações e desse modo, é possível que se preocupem em não tomar atitudes que potencializam a ocorrência de inundações e seus efeitos, como o descarte inadequado de lixo em rios, por exemplo, e ainda tomem providências no sentido de reduzir ou eliminar possíveis consequências de inundações, podendo evitar acidentes e até mesmo desastres naturais.

Ao colaborar para a construção de uma percepção de riscos "mais acurada" e orientar medidas, planos de ação que visem evitar ou pelo menos minimizar possíveis danos, a educação ambiental estará exercendo parte de seu papel, construindo valores sociais, conhecimentos, habilidades, atitudes e competências voltadas para a conservação do meio ambiente, para a qualidade de vida da sociedade e sua sustentabilidade.

\section{Referências}

BRASIL. Coordenação de Educação Ambiental do Ministério da Educação e do Desporto. A Implantação da Educação Ambiental no Brasil. Brasília, 1998.

BRASIL. Ministério da Educação. Salto para o futuro. Educação Ambiental no Brasil. Brasília, 2008.

BRASIL. Ministério da Educação. Educação Ambiental: aprendizes de sustentabilidade. Brasília, 2007.

BUSTUS, M.R.L. A Educação ambiental sob a ótica da gestão de recursos hídricos. São Paulo: Universidade de São Paulo, 2003. Tese (Doutorado em Engenharia Hidráulica e Sanitária)- Universidade de São Paulo, São Paulo,2003. 
CAMPOS, A.S. Educación y prevención de desastres. Red de Estúdios Sociales en Prevención de Desastres em América Latina, 1999. Disponível em: $<$ http://cidbimena.desastres.hn/docum/lared/libros/EducacionYPrevencionDeDe sastres-1.0.1.pdf >. Acesso em: 16 jul. 2014.

CARDOZO, M. Percepção de riscos ambientais de trabalhadores catadores de materiais recicláveis em um aterro controlado do município de Duque de Caxias/ RJ. 2009. Dissertação (Mestrado em Ciências) - Escola Nacional de Saúde Pública Sérgio Arouca, Rio de Janeiro, 2009.

CASTRO, C.M; PEIXOTO, M.N.O; RIO, G.A.P.; Riscos Ambientais e Geografia: conceituações, abordagens e escalas. Anuário do Instituto de Geociências. Rio de Janeiro: UFRJ, 2005

LOUREIRO, C.F.B; Trajetória e fundamentos da educação ambiental. São Paulo: Cortez, 2004.

MACHADO, L.M.C.P. A percepção do Meio Ambiente como suporte para a Educação Ambiental. In: POMPÊO, M.L.M. Perspectivas da limnologia no Brasil. São Luís: Editora União, 1999.

MEDEIROS, M.J. Diagnóstico da ocorrência de inundações no Brasil como ferramenta de planejamento: $O$ Atlas de Vulnerabilidade a inundações. In: Simpósio Brasileiro de Recursos Hídrico, 19, 2011, Maceió. Anais... Disponível em:<http://www.abrh.org.br/sgcv3/UserFiles/Sumarios/950b9f109521b7725767 d6cb4831b0b4 483cfd6912d3b182eb59128889d39caa.pdf>. Acesso: 09/07/14.

MORIN, E. Por uma reforma do pensamento. In: PENA-VEGA, A., NASCIMENTO, E. O Pensar Complexo: Edgar Morin e a crise da modernidade. Rio de Janeiro: Garamond, 1999. p.33.

PEDRINI, A.G. Educação Ambiental: reflexões e práticas contemporâneas. Rio de Janeiro: Vozes, 1998.

SANTOS, E.C. (coord.). Educação ambiental. Manaus: Edições UEA/ Editora Valer, 2007.

SOUZA, L.B. Percepção dos riscos de escorregamentos na Vila Mello Reis, Juís de Fora (MG): contribuição ao planejamento e à gestão urbanos. Tese (Doutorado em Geografia) - Universidade Estadual Paulista, Rio Claro, 2006.

SOUZA, L.B.; ZANELA, M.E. Percepção de riscos ambientais: teoria eaplicações. Fortaleza: Edições UFC, 2009.

VEYRET, D.J. Os riscos: o homem como agressor e vítima do meio ambiente. São Paulo: Ed. Contexto, 2007.

WHYTE, A.V.T. Perception. In: KATES, R.W.; AUSUBEL, J.H.; BERBERIAN, M. Climate impact assessment: studies of the interaction of climate and society. Chichester: John Wiley, 1985. p 107-131.

WIEDEMANN, P.M. Introduction risk perception and risk communication. Jülich: Programme Group Humans; Environment, Technology (MUT), Research Centre Jülich; 1993.

revista brasileira educação ambiental 